\title{
What are ventilation defects in asthma?
}

\author{
Sarah Svenningsen, ${ }^{1,2}$ Miranda Kirby, ${ }^{1,2}$ Danielle Starr, ${ }^{1}$ Harvey 0 Coxson, ${ }^{3}$ \\ Nigel A M Paterson, ${ }^{4}$ David G McCormack, ${ }^{4}$ Grace Parraga ${ }^{1,2}$
}

\begin{abstract}
- Additional material is published online only. To view please visit the journal online (http://dx.doi.org/10.1136/ thoraxjnl-2013-203711).

${ }^{1}$ Imaging Research

Laboratories, Robarts Research Institute, London, Ontario, Canada

${ }^{2}$ Department of Medical Biophysics, The University of Western Ontario, London, Ontario, Canada

${ }^{3}$ Department of Radiology and James Hogg Research Centre, University of British Columbia and Vancouver General Hospital, Vancouver, British Columbia, Canada

${ }^{4}$ Division of Respirology, Department of Medicine, The University of Western Ontario, London, Ontario, Canada
\end{abstract}

\section{Correspondence to} Dr G Parraga, Imaging Research Laboratories, Robarts Research Institute, 100 Perth Drive, London, Ontario, Canada N6A 5K8; gparraga@ robarts.ca

Received 10 April 2013 Revised 28 June 2013 Accepted 24 July 2013 Published Online First 16 August 2013

\footnotetext{
To cite: Svenningsen $S_{\text {, }}$ Kirby M, Starr D, et al. Thorax 2014;69:63-71.
}

\section{ABSTRACT \\ Background Hyperpolarised ${ }^{3} \mathrm{He}$ MRI provides a way to visualise regional pulmonary functional abnormalities that in asthma are thought to be related to airway morphological abnormalities. However, the exact aetiology of ventilation defects in asthma is not well understood.}

Objective To better understand the determinants of ventilation defects in asthma, we evaluated wellestablished clinical as well as ${ }^{3} \mathrm{He}$ MRI and X-ray CT airway measurements in healthy subjects and subjects with asthma.

Methods Thirty-four subjects ( $n=26$ subjects with asthma, $n=8$ healthy volunteers) underwent MRI, spirometry, plethysmography, fraction of exhaled nitric oxide analysis, methacholine challenge and CT for a region-of-interest proximal to ventilation defects. For subjects who consented to $C T$ ( $n=18$ subjects with asthma, $n=5$ healthy volunteers), we evaluated $3^{\text {rd }}$ to 5th generation airway wall area and wall thickness per cent and lumen area.

Results Seventeen subjects with asthma $(17 / 26=65 \%)$ had visually obvious evidence of ${ }^{3} \mathrm{He}$ ventilation defects prior to bronchoprovocation and nine subjects with asthma had no ventilation defects prior to bronchoprovocation $(9 / 26=35 \%)$. Subjects with asthma with defects were older $(p=0.01)$ with worse forced expiratory volume in $1 \mathrm{~s}\left(\mathrm{FEV}_{1}\right) /$ forced vital capacity $(p=0.0003)$, airways resistance $(p=0.004)$, fraction of exhaled nitric oxide $(p=0.03)$, greater bronchoprovocation concentration of methacholine that reduced $\mathrm{FEV}_{1}$ by $20 \%(\mathrm{p}=0.008)$ and wall thickness per cent $(p=0.02)$ compared with subjects with asthma without defects. There was a moderate correlation for wall area per cent with ventilation defect per cent $(r=0.43, p=0.04)$.

Conclusions Subjects with asthma with ${ }^{3} \mathrm{He}$ ventilation defects were older with significantly worse airway hyperresponsiveness, inflammation and airway remodelling but similar $\mathrm{FEV}_{1}$ as subjects with asthma without defects; hyperpolarised ${ }^{3} \mathrm{He}$ ventilation abnormalities were spatially and quantitatively related to abnormally remodelled airways.

\section{INTRODUCTION}

Asthma is typically diagnosed and characterised using the spirometry measurement ${ }^{12}$ of the forced expiratory volume in $1 \mathrm{~s}\left(\mathrm{FEV}_{1}\right)$. Although relatively simple and inexpensive, spirometry measurements provide a global estimate of the morphological changes in the small and medium-sized airways that are believed to be related to luminal inflammation, airway remodelling and constriction. We now realise

\section{Key messages}

What is the key question?

- In asthma, functional MRI using hyperpolarised ${ }^{3} \mathrm{He}$ gas has been used to visualise abnormal and heterogeneous inhaled gas distribution. Regions of signal void or ventilation defects, are believed to correspond to areas of the lung that are not ventilated and such defects have been shown to change in response to bronchoprovocation and bronchodilators. Notwithstanding this previous work, our current understanding of the aetiology and clinical meaning of ventilation defects in asthma is still very limited.

\section{What is the bottom line?}

- MRI and X-ray CT measurements of airway morphology and function were prospectively evaluated for healthy volunteers and subjects with asthma with and without ventilation defects. Seventeen subjects with asthma (17/ $26=65 \%$ ) had visually obvious ${ }^{3} \mathrm{He}$ ventilation defects; these subjects were significantly older, had significantly worse forced expiratory volume in 1 s/forced vital capacity, airways resistance, fraction of exhaled nitric oxide, and airway hyper-responsiveness, as well as more thickened airway walls and more narrowed airway lumen compared with nine subjects with asthma without ventilation defects.

\section{Why read on?}

- We report the quantitative and spatial relationship between ventilation defects with remodelled airways and with well-established measurements of asthma severity, and that subjects with asthma with ventilation defects were older and had more advanced or severe disease. Taken together, these findings provide us with a better understanding of the differences between subjects with asthma with similar $\mathrm{FEV}_{1}$ and the clinical meaning of ventilation defects in asthma.

using multiple breath nitrogen washout studies ${ }^{3} 4$ and pulmonary imaging methods, that functional abnormalities in asthma are in fact regionally heterogeneous, ${ }^{5-7}$ temporally persistent ${ }^{8-10}$ and that these abnormalities regionally respond to bronchoprovocation $^{7} 11{ }^{12}$ and to bronchodilator therapy. ${ }^{11} 13$ 
Thoracic X-ray CT has been used for over a decade as a noninvasive method to investigate structure-function relationships of asthmatic airways and has shown strong relationships between CT-derived airway measurements with inflammation, ${ }^{14} 15$ spirometry $^{14-21}$ and disease severity. ${ }^{14} 162022$ However, while these CT data are encouraging, they are still somewhat limited because it is well recognised that CT cannot resolve or measure airways beyond the fifth or sixth generation. Moreover, even using new lower dose and iterative reconstruction methods, ${ }^{23} \mathrm{CT}$ is not recommended for longitudinal studies and studies of young adults and children because of the potential risks associated with exposure to ionising radiation. Other pulmonary imaging methods such as nuclear medicine scintigraphy ${ }^{24-26}$ and positron emission tomography ${ }^{27}$ are also limited clinically because of inherently low spatial resolution.

Hyperpolarised ${ }^{3} \mathrm{He}$ MRI has been previously used to visualise heterogeneous and abnormal gas distribution in asthma. Regions of signal void or ventilation defects have been shown to be temporally persistent ${ }^{8-10}$ and to correlate significantly with spirometry, ${ }^{6} 2829$ disease severity ${ }^{6}$ and CT measurements of gas trapping. ${ }^{28}$ In addition, ${ }^{3} \mathrm{He}$ MRI also provides a way to perform intensive serial measurements due in part to its excellent safety profile, ${ }^{30}$ and the speed with which imaging can be performed. More specifically, ${ }^{3} \mathrm{He}$ MRI ventilation defects have been shown to increase from baseline following methacholine ${ }^{7} 11 \quad 12$ and exercise $^{12}$ challenge, and decrease from baseline following salbutamol administration. ${ }^{13}$ In asthma, the relationship between ventilation defects and patient outcomes such as exacerbation frequency and severity has not yet been evaluated; however this has been evaluated in chronic obstructive pulmonary disease. ${ }^{31}$ Recently, there has been growing interest in the clinical application of hyperpolarised gas MRI to assess treatment efficacy and furthermore to guide localised airway treatments in asthma. Preliminary work in severe asthma has shown improved ${ }^{3} \mathrm{He}$ gas distribution following localised bronchial thermoplasty treatment. ${ }^{32}$ While these results provide a strong foundation for the use of MRI in asthma research and patient care, a major drawback has been that we do not clearly understand the aetiology of MRI ventilation defects. ${ }^{33}$ It has been speculated that MRI ventilation defects reflect regional airway narrowing that may be the consequence of airway remodelling ${ }^{34}$; however, to our knowledge, the direct spatial and quantitative relationship between MRI ventilation defects and CT airway measurements has not been reported in patients with asthma. Therefore, our objective was to determine the underlying structural and clinical determinants of asthma ventilation abnormalities by evaluating well-established clinical and emerging imaging (hyperpolarised ${ }^{3} \mathrm{He}$ MRI and CT) measurements in healthy volunteers and subjects with asthma.

\section{METHODS}

\section{Study subjects}

All subjects provided written informed consent to a study protocol approved by the local research ethics board, and the study was compliant with the Personal Information Protection and Electronic Documents Act (Canada) and the Health Insurance Portability and Accountability Act (USA). Subjects were enrolled between 18 years and 60 years of age, including mild-to-moderate ${ }^{35}$ subjects with asthma, and healthy subjects with no history or diagnosis of asthma or any other chronic or current acute respiratory illness. Subjects with asthma were phenotyped from health records based on disease severity and symptoms from a tertiary care centre (interdisciplinary Allergy and Respirology asthma care centre); all subjects with asthma had a current physician diagnosis of asthma, were currently under treatment for asthma and had a positive methacholine challenge within the past 5 years. At a single visit, spirometry, plethysmography, fractional exhaled nitric oxide (FeNO) breath analysis and pulmonary CTwas performed within $30 \mathrm{~min}$ of MRI.

\section{Pulmonary function tests}

Spirometry and plethysmography were performed according to American Thoracic Society Guidelines ${ }^{36}$ using an ndd EasyOne spirometer (ndd Medizintechnik AG, Zurich, Switzerland) and a MedGraphics Elite Series plethysmograph (MedGraphics, St Paul, Minnesota, USA), respectively. FeNO was measured using a Niox Mino (Aerocrine USA, New Providence, New Jersey, USA). Methacholine challenge was performed as previously described $^{11}$ and the provocative concentration causing a $20 \%$ decrease in $\mathrm{FEV}_{1}\left(\mathrm{PC}_{20}\right)$ was determined. Borg and modified Medical Research Council dyspnoea scores were recorded.

\section{MRI}

MRI was performed on a whole body 3.0 T Discovery 750MR (General Electric Health Care, Milwaukee, Wisconsin, USA) system with broadband imaging capability, as previously described. ${ }^{37}$ Subjects were instructed to inhale a gas mixture from a $1.0 \mathrm{~L}$ Tedlar bag (Jensen Inert Products, Coral Springs, Florida, USA) from functional residual capacity, and image acquisition was performed in 8-15 s under breath-hold conditions. Conventional ${ }^{1} \mathrm{H}$ MRI was performed prior to hyperpolarised ${ }^{3} \mathrm{He}$ MRI, both methods are previously described. ${ }^{37}$

${ }^{3} \mathrm{He}$ MRI were qualitatively and quantitatively evaluated for ventilation abnormalities by a single trained observer. Upon qualitative inspection, subjects with asthma were classified into two groups, (1) subjects with asthma with no ventilation defects (ND) and (2) subjects with asthma with ventilation defects (AD). If ${ }^{3} \mathrm{He}$ gas was homogenously distributed throughout the lung and there were no visible ventilation defects the subject was classified as belonging to the ND group. In contrast, if ${ }^{3} \mathrm{He}$ gas was heterogeneously distributed throughout the lung and/or there were visually obvious ventilation defects, the subject was classified as belonging to the $\mathrm{AD}$ group. Quantitative evaluation of ${ }^{3} \mathrm{He}$ MRI was performed to estimate ventilation defect per cent (VDP) and ventilation heterogeneity using the coefficient of variation (COV). ${ }^{3} \mathrm{He}$ MRI semiautomated segmentation was performed to quantify lung volumes using custom software generated using MATLAB R2007b (The Mathworks, Natick, Massachusetts, USA), as previously described. ${ }^{38}$ As shown in figure $1,{ }^{3} \mathrm{He}$ static ventilation images were segmented using a K-means approach that classified voxel intensity values into five clusters ranging from signal void (cluster 1 (C1) or ventilation defect volume) to hyperintense signal (cluster 5 (C5)) to create a gas distribution cluster map. ${ }^{3} \mathrm{He}$ MRI VDP was generated using ventilation defect volume normalised to the thoracic cavity volume. Whole lung and regional VDP specific to the CT region-of-interest (ROI) were generated for each subject. Ventilation heterogeneity was estimated according to previously described methods ${ }^{7}$ using the COV. Briefly, a ventilated lung ROI was defined as gas distribution cluster-map clusters C2-C5. For each voxel within the ventilated lung ROI a local ventilation heterogeneity value was calculated by computing the COV of the signal intensity in the voxels $5 \times 5$ neighbourhood. Mean COV for each slice was calculated for each ${ }^{3} \mathrm{He}$ static ventilation slice and then averaged to obtain a single COV value for each subject.

CT

Following ${ }^{3} \mathrm{He}$ MRI, thoracic CT was performed with the same inhalation breath-hold volume and manoeuvre used for MRI, in order to match CT and MRI lung volume and anatomy. CT 

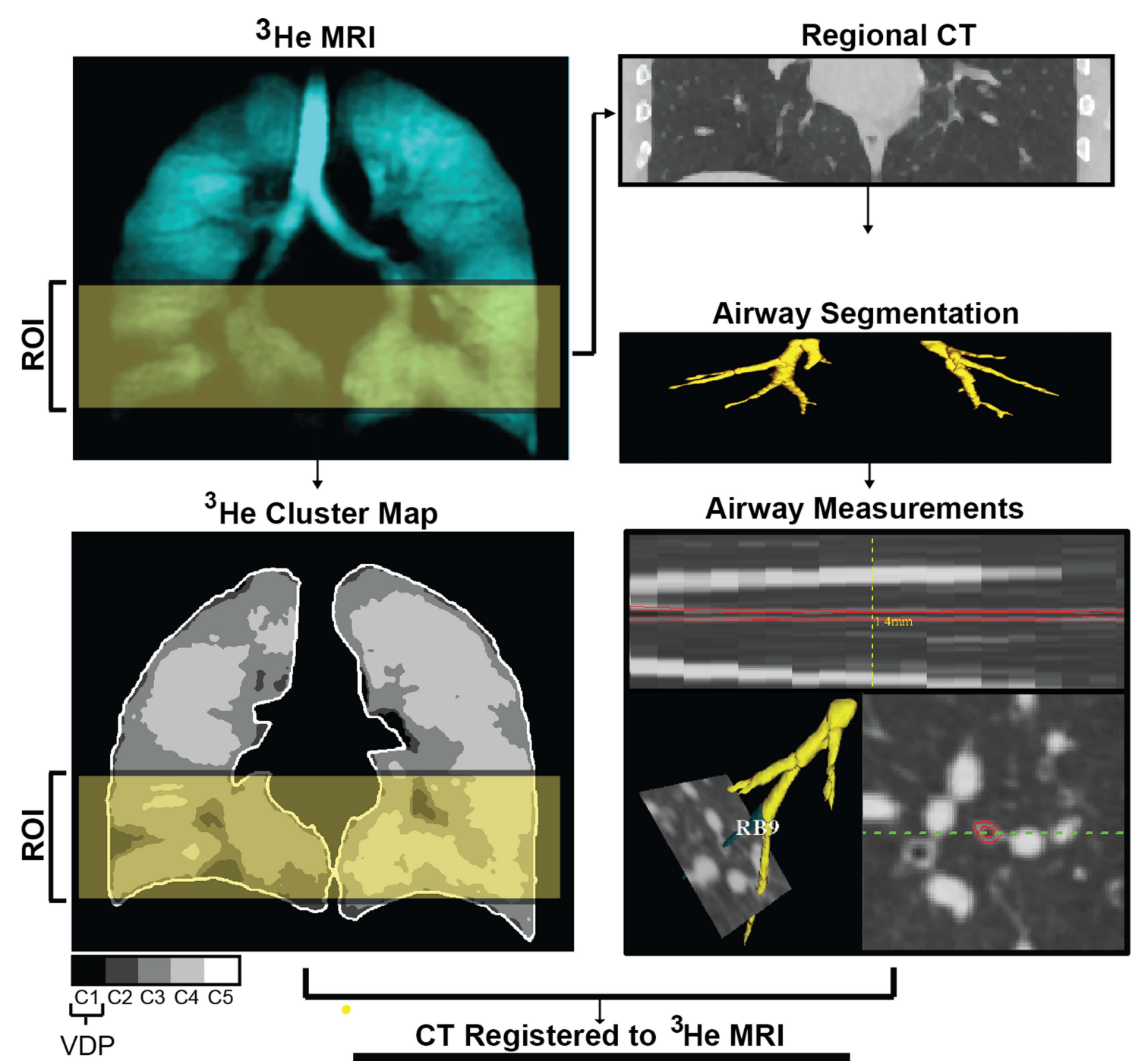

Airway Measurements

He Cluster Map

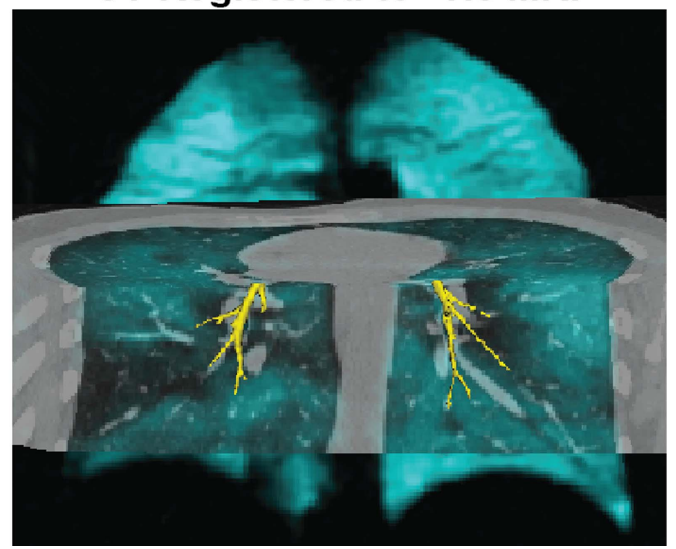

Figure 1 Schematic for ${ }^{3} \mathrm{He} \mathrm{MRI}$-Regional CT image acquisition, coregistration and analysis. A region-of-interest (ROI) (green-yellow rectangle) with ventilation defects was located using ${ }^{3} \mathrm{He}$ MRI. Following MRI, regional CT was acquired in that specific ROI. Ventilation defect per cent (VDP) was quantified for the whole lung and the CT-derived ROI and an automated airway tree segmentation algorithm was applied to obtain airway measurements. Using the carina and trachea as a landmark, the regional CT with rendered airways was rigidly coregistered with the corresponding MRI to confirm the spatial relationship between ventilation defects and corresponding airways.

imaging was performed in the supine position using a 64-slice Lightspeed VCT scanner (GEHC, Milwaukee, Wisconsin, USA) using a detector configuration of $64 \times 0.625 \mathrm{~mm}, 120 \mathrm{kVp}$, $100 \mathrm{~mA}, 0.5 \mathrm{~s}$ gantry rotation, and a pitch of 1.25 . To reduce the radiation dose, CT was obtained for a $4 \mathrm{~cm}$ axial ROI where there were visually obvious MRI ventilation defects. In the case where there were no visually obvious ventilation defects, the CT volume was acquired in the superior region of the lung. This approach resulted in CT volumes consisting of 32-80 slices and a total effective dose ranging from 0.37 to $0.14 \mathrm{~m} \mathrm{~Sv}$ (generated using the CT parameters and algorithm at http://www. impactscan.org).

CT image analysis was performed using Pulmonary Workstation V.2.0, (VIDA Diagnostics; Iowa City, Iowa, USA) to 
generate bronchial wall area per cent, wall thickness per cent and lumen area for all 3rd-5th generation segmental bronchi analysed and lumen area was normalised to body surface area. ${ }^{39}$ As shown in figure 1, an automated airway tree segmentation algorithm was applied with a manual seed-point in the airway lumen introduced if the trachea and main bronchus were not present in the image. For each subject, all airway segment measurements were averaged to report whole lung means. To identify potential spatial relationships between ${ }^{3} \mathrm{He}$ MRI ventilation defects and corresponding airways, CT-MRI coregistration was performed using 3D Slicer registration software (http://www. slicer.org). ${ }^{40}$

\section{Statistical methods}

Pulmonary function tests, MRI and CT measurements were compared between subject groups using unpaired Student $t$ tests performed using SPSS V.20.0 (IBM, Armonk, New York, USA). Linear regression $\left(r^{2}\right)$ and Spearman rank correlation coefficients (r) were performed using GraphPad Prism V.4.00 (Graphpad Software, San Diego, California, USA). Results were considered statistically significant when the probability of making a Type I error was less than $5 \%(\mathrm{p}<0.05)$.

\section{RESULTS}

We enrolled 34 subjects including 26 subjects with a clinical diagnosis of asthma and previous methacholine challenge results consistent with asthma, and 8 healthy volunteers. Table 1 shows subject demographic data, pulmonary function measurements and dyspnoea scores for the two subgroups, and a subject listing of all data is provided in the online supplementary table S1.

Upon qualitative visual inspection, 9 of the 26 subjects with asthma had ND and 17 had visually obvious AD. Figure 2 shows posterior, centre and anterior ${ }^{3} \mathrm{He}$ MRI static ventilation coronal slices (in blue) coregistered to the ${ }^{1} \mathrm{H}$ anatomical MRI (in grey scale) for a representative healthy volunteer as well as ND and AD subjects with asthma with yellow arrows identifying ventilation defects. For healthy volunteers and ND subjects with asthma, ${ }^{3} \mathrm{He}$ gas was homogeneously distributed throughout the lung whereas in contrast, AD subjects with asthma had visually

Table 1 Subject demographic characteristics for subjects with asthma and healthy volunteers

\begin{tabular}{|c|c|c|}
\hline & Healthy $(n=8)$ & Subjects with asthma $(n=26)$ \\
\hline \multicolumn{3}{|l|}{ Subject demographics } \\
\hline Age years $( \pm S D)$ & $34(11)$ & $35(11)$ \\
\hline Male/Female & $4 / 4$ & $12 / 14$ \\
\hline $\mathrm{BMI} \mathrm{kg} / \mathrm{m}^{2}( \pm \mathrm{SD})$ & $23(3)$ & $25(5)$ \\
\hline \multicolumn{3}{|l|}{ Pulmonary function tests } \\
\hline $\mathrm{FEV}_{1} \%_{\text {pred }}( \pm \mathrm{SD})$ & $102(10)$ & $84(15)$ \\
\hline FVC $\%_{\text {pred }}( \pm S D)$ & $103(10)$ & $93(11)$ \\
\hline $\mathrm{FEV}_{1} / \mathrm{FVC} \%( \pm \mathrm{SD})$ & $81(6)$ & $74(11)$ \\
\hline sRaw $\mathrm{cmH}_{2} \mathrm{O} \cdot \mathrm{s}( \pm \mathrm{SD})$ & $3.0(0.5)$ & $6.9(4.7)$ \\
\hline FeNO ppb $( \pm$ SD) & $18^{*}$ & $44(45)$ \\
\hline $\mathrm{PC}_{20} \mathrm{mg} / \mathrm{mL}( \pm \mathrm{SD})$ & $42.3(19.2)$ & $5.9(12.3)$ \\
\hline \multicolumn{3}{|l|}{ Dyspnoea scores } \\
\hline mMRC score $( \pm S D)$ & $0(0)$ & $1(1)$ \\
\hline Borg score $( \pm S D)$ & $0(0)$ & $0.5(1)$ \\
\hline
\end{tabular}

obvious ventilation heterogeneity and ventilation defects. Of the 8 healthy volunteers and 26 subjects with asthma evaluated, 2 healthy volunteers and 12 subjects with asthma underwent imaging across multiple time points ranging from 4 years prior, to 2 years following the study session reported here. In accordance with the study visit data presented here, healthy volunteers had NDs at their additional time point. All subjects with asthma who underwent multiple imaging time points were $\mathrm{AD}$ subjects with asthma and all of these subjects had ventilation defects at their additional time point and in the same spatial locations. Moreover, for all subjects with asthma with repeated imaging measurements $(n=12)$, VDP was not significantly different $(p=0.49)$ from measurements acquired and reported in this study.

As shown in table $2, \mathrm{AD}$ subjects were significantly older than ND subjects $(p=0.01)$ with significantly worse $\mathrm{FEV}_{1} /$ forced vital capacity $(\mathrm{FVC})(\mathrm{p}=0.0003)$, specific airways resistance (sRaw) $(p=0.004)$, FeNO $(p=0.03), P_{20}(p=0.008), C O V$ $(p=0.046)$, wall thickness per cent $(p=0.02)$ and lumen area normalised to body surface area $(p=0.04)$, but importantly there was no mean difference for $\operatorname{FEV}_{1} \quad(p=0.08)$, FVC $(p=0.71)$ or dyspnoea (modified Medical Research Council: $p=0.79$, Borg: $p=0.12$ ). As compared with healthy subjects, AD subjects had significantly worse $\mathrm{FEV}_{1}(\mathrm{p}=0.001), \mathrm{FEV}_{1} / \mathrm{FVC}$ $(p=0.003), \quad$ sRaw $\quad(p=0.003), \quad P_{20} \quad(p<0.0001), \quad$ COV $(p=0.007)$, wall area per cent $(p=0.001)$, wall thickness per cent $(p=0.04)$ and lumen area normalised to body surface area $(p=0.0003)$, but there was no significant difference for FVC $(p=0.06)$. ND subjects had significantly worse FVC $(p=0.04)$, $\mathrm{PC}_{20}(\mathrm{p}=0.02)$ and wall area per cent $(0.03)$ compared with healthy volunteers, but no significant difference for $\mathrm{FEV}_{1}$ $(p=0.09), \quad F_{1} /$ FVC $\quad(p=0.36), \quad$ sRaw $(p=0.36), \quad$ COV $(p=0.11)$, wall thickness per cent $(p=0.61)$ or lumen area normalised to body surface area $(p=0.26)$.

Figure 3 shows the correlations for $\mathrm{FEV}_{1}$ and sRaw with whole lung VDP, regional VDP and wall area per cent. $\mathrm{FEV}_{1}$ was significantly correlated with ${ }^{3} \mathrm{He}$ MRI VDP (whole lung: $\mathrm{r}=-0.61, \mathrm{p}=0.0002$; regional: $\mathrm{r}=-0.55, \mathrm{p}=0.006$ ) and wall area per cent $(r=-0.49, p=0.02)$. In addition, sRaw was significantly correlated with ${ }^{3} \mathrm{He}$ MRI VDP (whole lung: $r=0.77$, $\mathrm{p}<0.0001$; regional: $\mathrm{r}=0.81, \mathrm{p}<0.0001$ ) and wall area per cent $(\mathrm{r}=0.48, \mathrm{p}=0.02)$. Additionally, $\mathrm{FEV}_{1}$ and sRaw were significantly correlated with whole lung ${ }^{3} \mathrm{He}$ MRI COV $\left(\mathrm{FEV}_{1}: \mathrm{r}=\right.$ $-0.49, p=0.003$; sRaw: $r=0.59, p=0.0003)$. Figure 4 demonstrates that for all subjects wall area per cent was significantly correlated with whole lung $(\mathrm{r}=0.42, \mathrm{p}=0.046)$ and regional VDP $(r=0.43, p=0.04)$.

Figure 5 shows hyperpolarised ${ }^{3} \mathrm{He}$ MRI ventilation maps for four subjects with asthma with the ${ }^{3} \mathrm{He}$ MRI ventilation map in blue coregistered to the CT volume with the airway tree segmented in yellow. The qualitative spatial relationship between ventilation defects (yellow arrows) and remodelled airways (white arrows) is shown.

\section{DISCUSSION}

To better understand the structural and clinical determinants of MRI ventilation defects in asthma, and, in turn, what it might mean for a subject with asthma to have ventilation defects, we evaluated well-established clinical measurements and emerging CT and ${ }^{3} \mathrm{He}$ MRI measurements of airway structure and function.

We think that it is interesting that $9 / 26$ (35\%) subjects with clinical findings and methacholine challenge results diagnostic of asthma had a ${ }^{3} \mathrm{He}$ MRI gas distribution that was qualitatively 

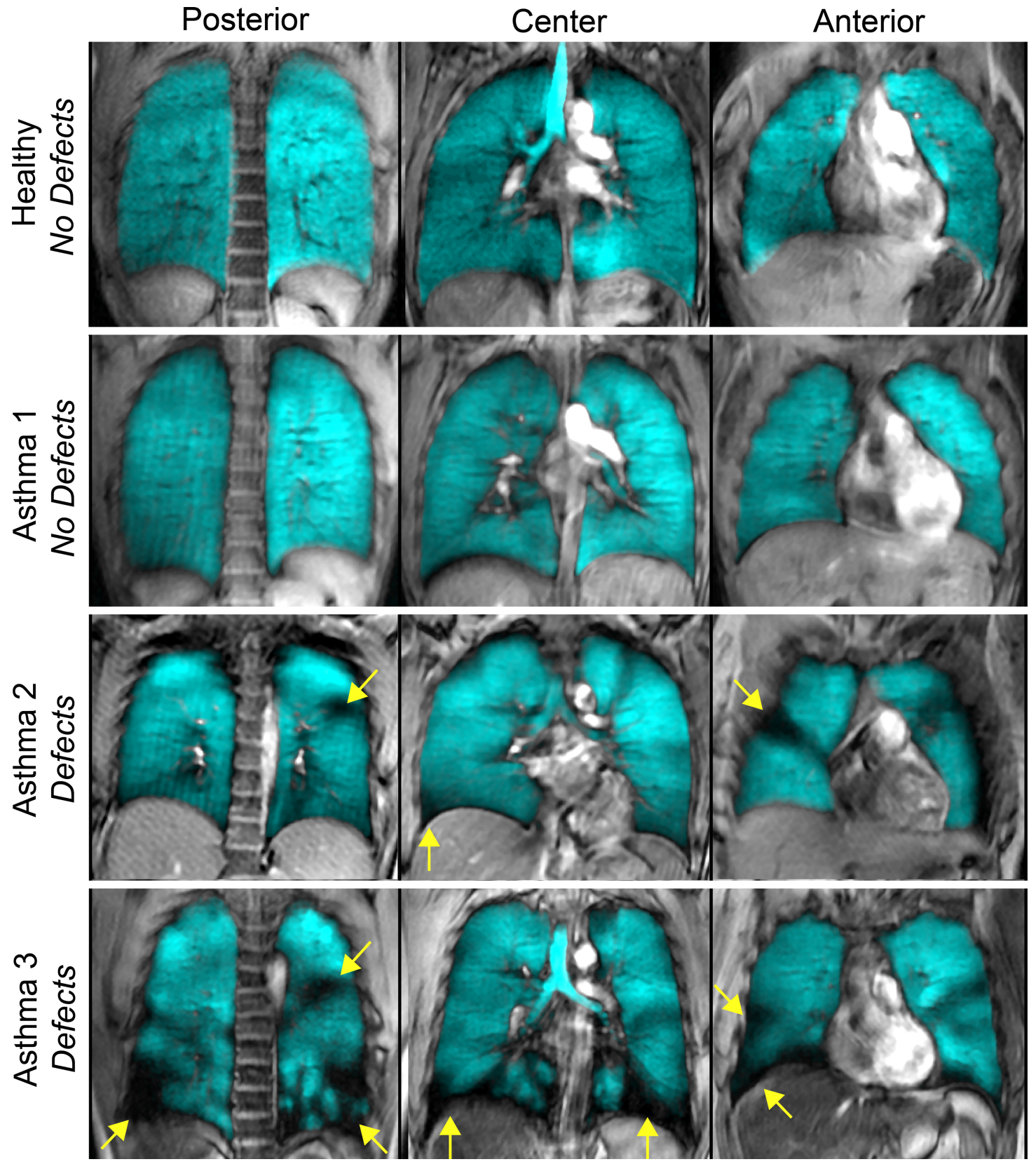

Figure 2 Hyperpolarised ${ }^{3} \mathrm{He}$ MRI of a representative healthy volunteer and subjects with asthma. ${ }^{3} \mathrm{He}$ MRI gas distribution (in blue) registered to the ${ }^{1} \mathrm{H}$ MRI of the thorax (in grey scale) for posterior, centre and anterior coronal slices for a representative healthy volunteer, a subject with asthma with no ventilation defects, and two subjects with asthma with ventilation defects. Yellow arrows identify ventilation defects. Healthy volunteer: 27 year-old woman, forced expiratory volume in $1 \mathrm{~s}\left(\mathrm{FEV}_{1}\right)=105 \%$ pred, $\mathrm{FEV}_{1} /$ forced vital capacity $(\mathrm{FVC})=85 \%$, specific airways resistance (sRaw) $=2.60 \mathrm{cmH}_{2} \mathrm{O}$ s. Subject with asthma 1 No Defects: 23 year-old woman, $\mathrm{FEV}_{1}=82 \%_{\text {pred, }} \mathrm{FEV} / \mathrm{FVC}=79 \%$, sRaw $=3.80 \mathrm{cmH} \mathrm{CH}_{2} \mathrm{~s}$. Subject with asthma 2 Defects: 25 year-old woman, $\mathrm{FEV}_{1}=87 \%$ pred, $\mathrm{FEV}_{1} / \mathrm{FVC}=69 \%$, sRaw $=5.36 \mathrm{cmH}_{2} \mathrm{O}$ s. Subject with asthma 3 Defects: 42 year-old man, $\mathrm{FEV}_{1}=72 \%_{\text {pred }}, \mathrm{FEV}_{1} / \mathrm{FVC}=65 \%$, sRaw $=13.85 \mathrm{cmH}_{2} \mathrm{O} \mathrm{s}$.

and quantitatively (VDP and COV) similar to healthy volunteers. It is important to note that all of the healthy volunteers had a homogenous gas distribution with no visual or quantitative evidence of ventilation defects, which is in agreement with previous work at our centre ${ }^{1141-43}$ and others. ${ }^{5744}$ In contrast, and as expected based on previous investigations, ${ }^{5-9} 11 \quad 12$ the remaining 17/26 (65\%) subjects with asthma had obvious ventilation abnormalities. This observation prompted us to ask the question: Are subjects with asthma with ventilation defects different from subjects with asthma without ventilation defects? The results here suggest that subjects with asthma with ventilation defects are older, with worse $\mathrm{FEV}_{1} / \mathrm{FVC}$, (but similar $\mathrm{FEV}_{1}$ ), and greater airways resistance, airway responsiveness and airway inflammation/remodelling. Such findings suggest that ventilation defects may reflect long-term or progressive airway remodelling in patients with a longer history of disease or perhaps more severe or advanced disease. Regardless, the constellation of clinical and imaging findings in these subjects with asthma suggests that more aggressive therapy or compliance to therapy is required. This is a hypothesis that can be tested in future imaging studies of older subjects and/or subjects with more severe asthma. 
Table 2 Subject demographic characteristics, pulmonary function, hyperpolarised ${ }^{3} \mathrm{He}$ MRI and X-ray CT airways measurements for subjects with asthma and healthy volunteers

\begin{tabular}{|c|c|c|c|c|c|c|}
\hline & \multirow{2}{*}{ Healthy $(n=8)$} & \multicolumn{2}{|c|}{ Asthma $(n=26)$} & \multicolumn{3}{|c|}{ Significance of difference* ( $p$ value) } \\
\hline & & ND $(n=9)$ & $A D(n=17)$ & HV vs ND & HV vs $A D$ & ND vs $A D$ \\
\hline \multicolumn{7}{|l|}{ Subject demographics } \\
\hline Age years $( \pm S D)$ & $34(11)$ & $27(8)$ & $39(11)$ & 0.19 & 0.29 & 0.01 \\
\hline Male/Female & $4 / 4$ & $2 / 7$ & $10 / 7$ & - & - & - \\
\hline \multicolumn{7}{|l|}{ Pulmonary function tests } \\
\hline $\mathrm{FEV}_{1} \%_{\text {pred }}( \pm \mathrm{SD})$ & $102(10)$ & $91(13)$ & $81(14)$ & 0.09 & 0.001 & 0.08 \\
\hline FVC $\%_{\text {pred }}( \pm S D)$ & $103(10)$ & $92(10)$ & $94(11)$ & 0.04 & 0.06 & 0.71 \\
\hline $\mathrm{FEV}_{1} / \mathrm{FVC} \%( \pm \mathrm{SD})$ & $81(6)$ & $84(7)$ & $69(10)$ & 0.36 & 0.003 & 0.0003 \\
\hline sRaw $\mathrm{cmH}_{2} \mathrm{O} \cdot \mathrm{s}( \pm \mathrm{SD})$ & $2.96(0.53)$ & $3.42(1.22)$ & $8.51(4.95)$ & 0.36 & 0.003 & 0.004 \\
\hline FeNO ppb $( \pm$ SD $)$ & $18 t$ & $17(9) \ddagger$ & $60(50) \S$ & - & - & 0.03 \\
\hline $\mathrm{PC}_{20} \mathrm{mg} / \mathrm{mL}( \pm \mathrm{SD})$ & $42.3(19.2)$ & $14.3(16.8)$ & $1.4(3.9)$ & 0.02 & $<0.0001$ & 0.008 \\
\hline \multicolumn{7}{|l|}{ Dyspnoea } \\
\hline mMRC score $( \pm S D)$ & $0.0(0.0)$ & $0.7(0.7)$ & $0.8(1.0)$ & 0.02 & 0.04 & 0.79 \\
\hline Borg score $( \pm S D)$ & $0.1(0.2)$ & $0.2(0.3)$ & $0.7(0.8)$ & 0.28 & 0.047 & 0.12 \\
\hline \multicolumn{7}{|l|}{${ }^{3} \mathrm{He}$ MRI } \\
\hline Whole lung VDP\% $( \pm S D)$ & $1.22(0.19)$ & $1.31(0.32)$ & $4.26(3.28)$ & - & - & - \\
\hline Regional VDP\% ( $( \pm \mathrm{SD}) \boldsymbol{\|}$ & $0.94(0.28)$ & $0.95(0.40)$ & $2.35(0.98)$ & - & - & - \\
\hline Whole lung COV $( \pm$ SD) & $0.22(0.02)$ & $0.23(0.01)$ & $0.26(0.03)$ & 0.11 & 0.007 & 0.046 \\
\hline \multicolumn{7}{|l|}{ Regional CTף } \\
\hline WA\% $\%( \pm S D)$ & $62(2)$ & $66(3)$ & $69(3)$ & 0.03 & 0.001 & 0.08 \\
\hline WT\% ( & $24(4)$ & $25(2)$ & $29(4)$ & 0.61 & 0.04 & 0.02 \\
\hline 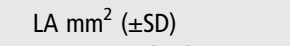 & $18(3)$ & $14(6)$ & $11(4)$ & 0.19 & 0.002 & 0.12 \\
\hline LA/BSA $\mathrm{mm}^{2} / \mathrm{m}^{2}( \pm \mathrm{SD})$ & $10(2)$ & $8(3)$ & $6(2)$ & 0.26 & 0.0003 & 0.04 \\
\hline
\end{tabular}

* Significance of difference $(p<0.05)$ determined using a $t$ test.

All statistically significant $p$ values are bold.

$+n=1 ; \neq n=8 ; \S n=13 ; \uparrow H V: n=5 ; N D: n=9 ; A D: n=9$

$\%$ pred, per cent predicted; $A D$, subjects with asthma with ventilation defects; $B S A$, body surface area; COV, coefficient of variation; FeNO, fraction of exhaled nitric oxide; FEV expiratory volume in $1 \mathrm{~s}$; FVC, forced vital capacity; HV, healthy volunteers; LA, lumen area; mMRC, modified Medical Research Council; ND, subjects with asthma with no ventilation defects; $\mathrm{PC}_{20}$, provocative concentration of methacholine sufficient to induce a $20 \%$ decrease in $\mathrm{FEV}_{1}$; sRaw, specific airways resistance; VDP, ventilation defect per cent; WA\%, wall area per cent; WT\%, wall thickness per cent.

A number of studies have quantitatively investigated asthma airway structure using CT and showed that bronchial wall thickness was related to asthma severity, duration of disease and airflow obstruction. ${ }^{14-22}$ Similarly, ${ }^{3} \mathrm{He}$ MRI has previously shown that ventilation defects were related to asthma severity ${ }^{6}$ and in a preliminary report, ${ }^{45}$ half of a small group of subjects with asthma (7/15) showed no obvious ventilation defects, with significantly different bronchial wall thickness (but not bronchial wall area) compared with subjects with asthma with ventilation defects. Here, we prospectively acquired MRI and CT within about 30 min using the same lung volume and breath-hold manoeuvre to try to mimic the same airway and parenchyma dimensions using both imaging methods. We must consider that because ${ }^{3} \mathrm{He}$ gas is itself, highly diffusive and may penetrate even narrowed airways, there is the possibility that even when bronchial wall thickness and lumen area are abnormal, some ${ }^{3} \mathrm{He}$ gas ventilation is possible. In support of this explanation, we note the recent report of indirect or collateral ventilation in chronic obstructive pulmonary disease that was directly visualised using hyperpolarised ${ }^{3} \mathrm{He} \mathrm{MRI}^{46}$ - likely possible only because the timeframe for imaging was relatively long and ${ }^{3} \mathrm{He}$ gas is highly diffusive.

We also observed that regional CT airway morphology and ${ }^{3} \mathrm{He}$ ventilation defect measurements were significantly correlated. This important finding suggests that there is a relationship between airways that are remodelled and/or constricted and ventilation defects. Previous studies have demonstrated that focal regions of hyperlucency on CT (likely related to gas trapping) were spatially correlated with ${ }^{3} \mathrm{He}$ MRI ventilation defects ${ }^{28}$ and bronchoalveolar lavage had higher total and per cent neutrophils in areas of the lung with greater ventilation defects, suggestive of increased inflammation. Although we observed significant relationships between airway dimensions and defects, these relationships were modest, perhaps because of the heterogeneity of asthma and the patients with asthma evaluated here, or because of the relatively low dose partial CT ROI that was used. It is important to acknowledge that in asthma, the airways from the large bronchi to the alveolar ducts may be involved, ${ }^{47}$ thus using CT to measure airway dimensions has limitations because CT cannot spatially resolve the small airways $(<2 \mathrm{~mm})$ sufficiently to provide accurate measurements. In addition to small and heterogeneously distributed ventilation defects, some of the subjects with asthma evaluated here presented large wedge-shaped defects; these have previously been reported using single photon emission CT imaging with Technegas ${ }^{25}$ and are believed to be the result of subsegmental airway narrowing. Following MRI-CT registration we were able to identify and quantify subsegmental bronchi that were spatially related to ventilation defects. Larger 'subsegmental' ventilation defects may be the result of proximal remodelled subsegmental airways feeding these regions of signal void. Unfortunately, due to the limitations of the spatial resolution of the CT images, we cannot comment on the structure of the smaller airways distal to the subsegmental airways quantified here, which may further contribute to the abnormal gas distributions observed.

Large and temporally persistent ${ }^{3} \mathrm{He}$ ventilation defects provide excellent targets for therapy and could potentially guide localised airway treatments such as bronchial thermoplasty. 

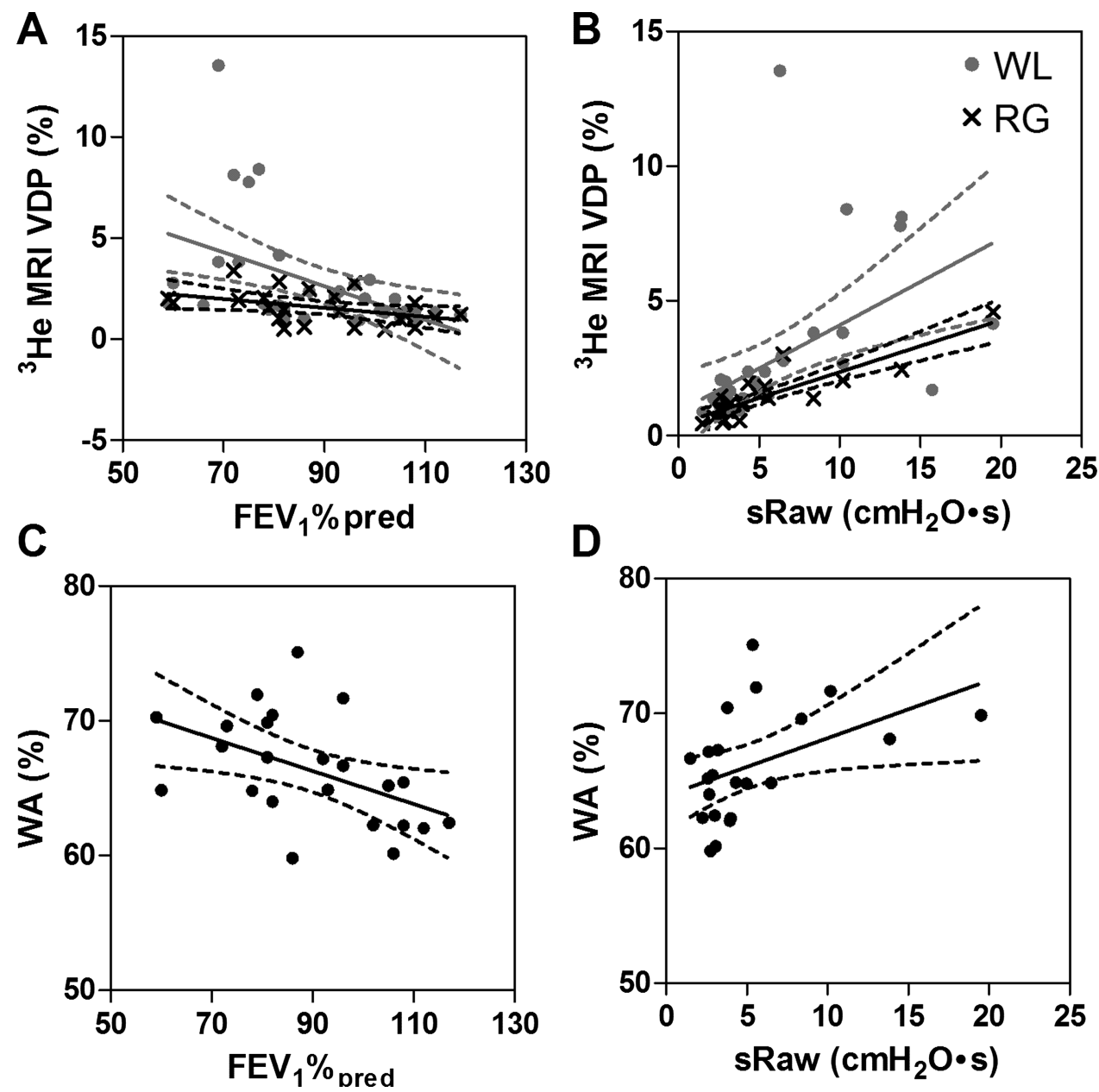

Figure 3 Relationships of MRI and CT measurements with forced expiratory volume in $1 \mathrm{~s}\left(\mathrm{FEV}_{1}\right)$ and airways resistance. (A) Negative relationship between ${ }^{3} \mathrm{He}$ MRI ventilation defect per cent (VDP) and FEV $\%$ pred (whole lung (WL): $r=-0.61, r^{2}=0.20, p=0.0002 ;$ regional $(R G): r=-0.55, r^{2}=0.26$, $p=0.006$ ). (B) Positive relationship between ${ }^{3}$ He MRI VDP and specific airways resistance (sRaw) (WL: $r=0.77, r^{2}=0.62, p<0.0001 ; R G: r=0.81$, $\left.r^{2}=0.75, p<0.0001\right)$. (C) Negative relationship between wall area per cent $(W A \%)$ and $F E V_{1} \%_{\text {pred }}\left(r=-0.49, r^{2}=0.23, p=0.02\right)$. (D) Positive relationship between $W A \%$ and specific airways resistance (sRaw) $\left(r=0.48, r^{2}=0.21, p=0.02\right)$.

Although we have focused our attention on ventilation defects, areas of hyperintense signal intensity are often observed in subjects with asthma in conjunction with ventilation defects. Similar to regions of signal void, to our knowledge, the underlying aetiology of these regions has not been investigated. We hypothesise that hyperintense signal may be due to hyperinflation and note that investigation of these regions is warranted in asthma.

We recognise and acknowledge that this work was limited by the relatively small number of subjects evaluated, although we note that this is the single largest prospective study that directly compared CT and ${ }^{3} \mathrm{He}$ MRI in subjects with asthma and healthy subjects. Furthermore, the subjects evaluated here were enrolled from a multidisciplinary asthma care centre and therefore they represent a diverse group of subjects with asthma that have been mainly referred to improve asthma symptoms and control. As shown in figure 3 , there was a single subject with elevated VDP as compared with the other $\mathrm{AD}$ subjects and we confirmed that this 42 year-old man had experienced an asthma exacerbation that required hospitalisation approximately 5 months prior to hyperpolarised ${ }^{3} \mathrm{He}$ MRI performed here. This subject's asthma was previously well controlled and the exacerbation was determined to be the result of sudden cessation of asthma medication. It is important to note that the relationships presented in

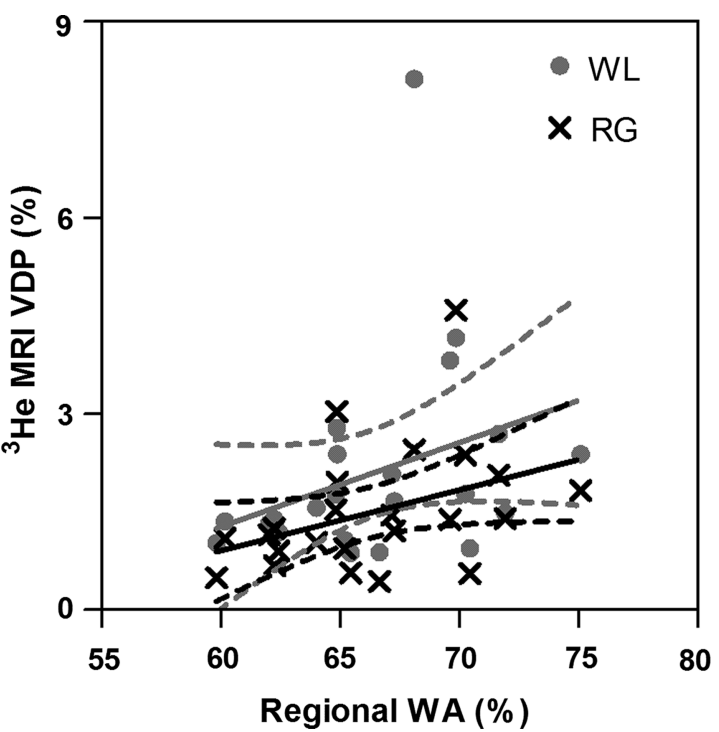

Figure 4 Relationship between ${ }^{3} \mathrm{He}$ MRI ventilation defect per cent (VDP) and CT-derived wall area per cent (WA\%). WA\% was significantly correlated with whole lung ${ }^{3} \mathrm{He}$ MRI VDP $\left(r=0.42, r^{2}=0.11\right.$, $\mathrm{p}=0.046)$ and regional ${ }^{3} \mathrm{He}$ MRI VDP $\left(r=0.43, \mathrm{r}^{2}=0.15, \mathrm{p}=.04\right)$. Dotted lines represent the $95 \% \mathrm{Cls}$ of the regression line. 

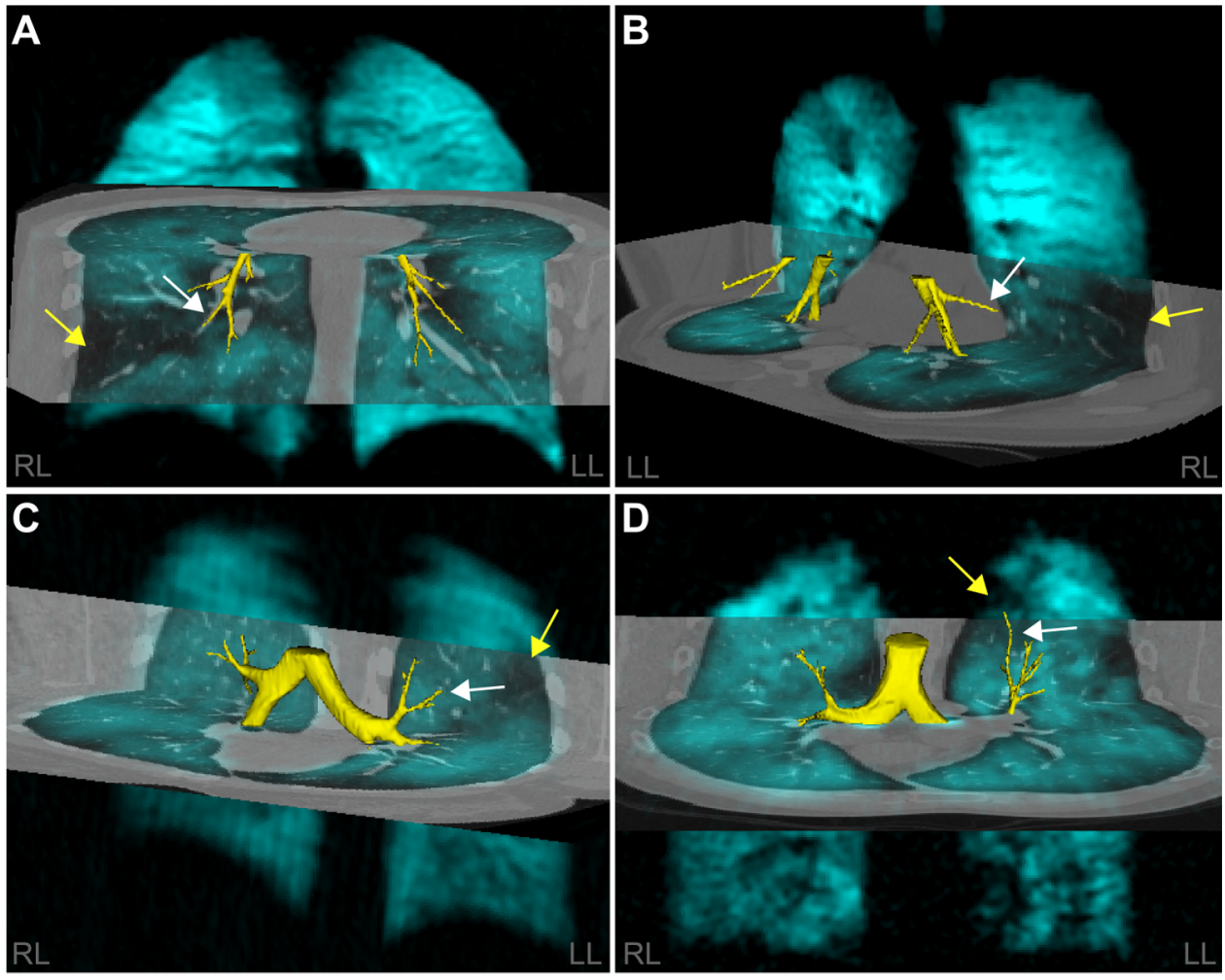

Figure 5 Spatial relationship between ventilation defects and airways for four representative subjects with asthma with ventilation defects. ${ }^{3}$ He MRI gas distribution (in blue) registered to the regional CT of the thorax (in grey scale) with the airway tree segmented in yellow. Airway measurements are for the specific airway (white arrow) spatially related to the ventilation defect (yellow arrow) of interest. (A) 29 year-old man forced expiratory volume in $1 \mathrm{~s}\left(\mathrm{FEV}_{1}\right)=81 \%$ pred, regional ventilation defect per cent $(\mathrm{VDP})=5 \%$, wall area $=71 \%$, lumen area $=5 \mathrm{~mm}$; $(\mathrm{B}) 49$ year-old man, $\mathrm{FEV}_{1}=60 \%$ pred, regional VDP=3\%, wall area $=67 \%$, lumen area $=12 \mathrm{~mm}^{2}$; (C) 25 year-old woman, $\mathrm{FEV}=87 \%$ pred, regional VDP=2\%, wall area $=75 \%$, lumen area $=5 \mathrm{~mm}^{2}$; (D) 58 year-old man, $\mathrm{FEV}_{1}=73 \%$ pred, regional $\mathrm{VDP}=1 \%$, wall area $=70 \%$, lumen area $=5 \mathrm{~mm}^{2}$.

figure 3 remain statistically significant when this outlier is removed from the analysis. Certainly, this is a hypothesisgenerating study and therefore marginally significant $p$ values should be interpreted with caution, and larger studies are required for more extensive phenotyping and characterisation of subjects with asthma and to test the hypotheses generated here. We must also acknowledge that our analysis was limited because of the acquisition of partial CT thoracic volumes.

In summary, our results showed that subjects with asthma with ${ }^{3} \mathrm{He}$ MRI ventilation abnormalities were older, with greater airway hyper-responsiveness, and worse measurements of $\mathrm{FEV}_{1} / \mathrm{FVC}$ and airways resistance/inflammation as well as abnormally remodelled airways in comparison with subjects with asthma with ND. Hyperpolarised ${ }^{3} \mathrm{He}$ ventilation abnormalities were spatially and quantitatively related to remodelled airways in subjects with asthma providing a better understanding of the aetiology of heterogeneous ventilation abnormalities in asthma and the clinical meaning of these abnormalities in subjects with asthma with similar $\mathrm{FEV}_{1}$.

Acknowledgements We thank S McKay and S Halko for clinical coordination and clinical database management, A Wheatley for production and dispensing of ${ }^{3} \mathrm{He}$ gas and T Szekeres for MRI of research volunteers.

Contributors SS was responsible for data acquisition, analysis and interpretation, drafting and final approval of the manuscript. MK was responsible for data acquisition, statistical analysis and interpretation, drafting and final approval of the manuscript. DS was responsible for data analysis and interpretation, and final approval of the manuscript. HOC was responsible for data interpretation and final approval of the manuscript. NAMP was responsible for clinical/physiological interpretation of the data, drafting and final approval of the manuscript. DGM was responsible for clinical/physiological interpretation of the data, subject safety, good clinical practice, drafting and final approval of the manuscript. GP, the Principal Investigator, was responsible for conception and design, data acquisition and analysis plan and interpretation, drafting and final revisions of manuscript and final approval as well as guarantor of integrity of the data as well as responsible for Good Clinical Practice.

Funding SS was supported by a National Science and Engineering Research Council of Canada (NSERC) Alexander Graham Bell Canada Graduate Scholarship, DS was supported by an NSERC Discovery Grant, and MK was supported by a NSERC Doctoral Postgraduate Scholarship. GP also gratefully acknowledges funding from the Canadian Institute of Health Research (CIHR) New Investigator Award, and operating funding from the Canadian Lung Association and Ontario Research Fund, Research Excellence Award.

Competing interests None.

Ethics approval The University of Western Ontario Research Ethics Board for Health Sciences Research Involving Human Subjects.

Provenance and peer review Not commissioned; externally peer reviewed.

\section{REFERENCES}

1 Busse WW. Asthma diagnosis and treatment: filling in the information gaps. J Allergy Clin Immunol 2011;128:740-50.

2 Celli BR. The importance of spirometry in COPD and asthma: effect on approach to management. Chest 2000;117:15S-9S.

3 Bourdin A, Paganin F, Prefaut C, et al. Nitrogen washout slope in poorly controlled asthma. Allergy 2006;61:85-9.

4 Farah CS, King GG, Brown NJ, et al. The role of the small airways in the clinical expression of asthma in adults. J Allergy Clin Immunol 2012;129:381-87.

5 Altes TA, Powers PL, Knight-Scott J, et al. Hyperpolarized 3He MR lung ventilation imaging in asthmatics: preliminary findings. J Magn Reson Imaging 2001;13:378-84.

6 de Lange EE, Altes TA, Patrie JT, et al. Evaluation of asthma with hyperpolarized helium-3 MRI: correlation with clinical severity and spirometry. Chest 2006;130:1055-62. 
7 Tzeng YS, Lutchen K, Albert M. The difference in ventilation heterogeneity between asthmatic and healthy subjects quantified using hyperpolarized 3He MRI. J App/ Physiol 2009;106:813-22.

8 de Lange EE, Altes TA, Patrie JT, et al. The variability of regional airflow obstruction within the lungs of patients with asthma: assessment with hyperpolarized helium-3 magnetic resonance imaging. J Allergy Clin Immunol 2007;119:1072-78.

9 de Lange EE, Altes TA, Patrie JT, et al. Changes in regional airflow obstruction over time in the lungs of patients with asthma: evaluation with ${ }^{3} \mathrm{He}$ MR imaging. Radiology 2009;250:567-75.

10 Wheatley A, McKay S, Mathew L, et al. Hyperpolarized helium-3 magnetic resonance imaging of asthma: short-term reproducibility. Proceedings of the SPIE: Medical Imaging 2008: Physiology, Function, and Structure from Medical Images 2008;69161. doi:10.1117/12.771138

11 Costella S, Kirby M, Maksym GN, et al. Regional pulmonary response to a methacholine challenge using hyperpolarized ${ }^{3} \mathrm{He}$ magnetic resonance imaging Respirology 2012;17:1237-46.

12 Samee $S$, Altes T, Powers $P$, et al. Imaging the lungs in asthmatic patients by using hyperpolarized helium-3 magnetic resonance: assessment of response to methacholine and exercise challenge. J Allergy Clin Immunol 2003;111:1205-11.

13 Svenningsen S, Kirby M, Starr D, et al. Hyperpolarized ${ }^{3} \mathrm{He}$ and ${ }^{129}$ Xe MRI: differences in asthma before bronchodilation. J Magn Reson Imaging Published Online First: 15 April 2013. doi:10.1002/jmri.24111

14 Aysola RS, Hoffman EA, Gierada D, et al. Airway remodeling measured by multidetector $\mathrm{CT}$ is increased in severe asthma and correlates with pathology. Chest 2008:134:1183-91.

15 Niimi A, Matsumoto $H$, Amitani R, et al. Airway wall thickness in asthma assessed by computed tomography. Relation to clinical indices. Am J Respir Crit Care Med 2000;162:1518-23

16 Awadh N, Muller NL, Park CS, et al. Airway wall thickness in patients with near fatal asthma and control groups: assessment with high resolution computed tomographic scanning. Thorax 1998;53:248-53.

17 de Jong PA, Muller NL, Pare PD, et al. Computed tomographic imaging of the airways: relationship to structure and function. Eur Respir J 2005;26:140-52.

18 Gono H, Fujimoto K, Kawakami S, et al. Evaluation of airway wall thickness and air trapping by HRCT in asymptomatic asthma. Eur Respir J 2003;22:965-71.

19 Kosciuch J, Krenke R, Gorska K, et al. Relationship between airway wall thickness assessed by high-resolution computed tomography and lung function in patients with asthma and chronic obstructive pulmonary disease. J Physiol Pharmacol 2009;60 (Suppl 5):71-6.

20 Little SA, Sproule MW, Cowan MD, et al. High resolution computed tomographic assessment of airway wall thickness in chronic asthma: reproducibility and relationship with lung function and severity. Thorax 2002:57:247-53.

21 Ueda T, Niimi A, Matsumoto $H$, et al. Role of small airways in asthma: investigation using high-resolution computed tomography. J Allergy Clin Immunol 2006;118:1019-25

22 Mitsunobu F, Tanizaki Y. The use of computed tomography to assess asthma severity. Curr Opin Allergy Clin Immunol 2005;5:85-90.

23 Katsura M, Matsuda I, Akahane M, et al. Model-based iterative reconstruction technique for radiation dose reduction in chest $\mathrm{CT}$ : comparison with the adaptive statistical iterative reconstruction technique. Eur Radiol 2012;22:1613-23.

24 King GG, Eberl S, Salome CM, et al. Airway closure measured by a technegas bolus and SPECT. Am J Respir Crit Care Med 1997;155:682-88

25 King GG, Eberl S, Salome CM, et al. Differences in airway closure between normal and asthmatic subjects measured with single-photon emission computed tomography and technegas. Am J Respir Crit Care Med 1998;158:1900-06.

26 Pellegrino R, Biggi A, Papaleo A, et al. Regional expiratory flow limitation studied with Technegas in asthma. J App/ Physiol 2001:91:2190-98.

27 Venegas JG, Winkler T, Musch G, et al. Self-organized patchiness in asthma as a prelude to catastrophic shifts. Nature 2005:434:777-82.
28 Fain SB, Gonzalez-Fernandez G, Peterson ET, et al. Evaluation of structure-function relationships in asthma using multidetector $\mathrm{CT}$ and hyperpolarized He-3 MRI. Acad Radiol 2008:15:753-62.

29 Tgavalekos NT, Musch G, Harris RS, et al. Relationship between airway narrowing, patchy ventilation and lung mechanics in asthmatics. Eur Respir J 2007:29:1174-81.

30 Lutey BA, Lefrak SS, Woods JC, et al. Hyperpolarized 3He MR imaging: physiologic monitoring observations and safety considerations in 100 consecutive subjects. Radiology 2008;248:655-61.

31 Kirby M, Kanhere N, Etemad-Rezai R, et al. Hyperpolarized helium-3 magnetic resonance imaging of chronic obstructive pulmonary disease exacerbation. J Magn Reson Imaging 2013;37:1223-7.

32 Sheshadri A, Thomen R, Kozlowski J, et al. Ventilation defects with hyperpolarized 3helium MRI in severe asthma before and after bronchial thermoplasty. Am J Respir Crit Care Med 2013;187. doi:10.1164/ajrccm-conference.2013.187.1_ MeetingAbstracts.A5443

33 Pare PD, Nagano T, Coxson HO. Airway imaging in disease: Gimmick or useful tool? J Appl Physiol 2012;113:636-46.

34 Aysola $\mathrm{R}$, de Lange $\mathrm{EE}$, Castro $\mathrm{M}$, et al. Demonstration of the heterogeneous distribution of asthma in the lungs using CT and hyperpolarized helium-3 MRI. J Magn Reson Imaging 2010;32:1379-87.

35 Busse WW. National Asthma Education and Prevention Program Expert Panel Report 3 Guidelines for the Diagnosis and Management of Asthma, Summary Report 2007. J Allergy Clin Immunol 2007;120:S93-S140.

36 Miller MR, Hankinson J, Brusasco V, et al. Standardisation of spirometry. Eur Respir J 2005;26:319-38.

37 Parraga G, Ouriadov A, Evans A, et al. Hyperpolarized 3 He ventilation defects and apparent diffusion coefficients in chronic obstructive pulmonary disease: preliminary results at 3.0 Tesla. Invest Radiol 2007:42:384-91.

38 Kirby M, Heydarian M, Svenningsen $\mathrm{S}$, et al. Hyperpolarized (3)He magnetic resonance functional imaging semiautomated segmentation. Acad Radiol 2012;19:141-52.

39 King GG, Muller NL, Pare PD. Evaluation of airways in obstructive pulmonary disease using high-resolution computed tomography. Am J Respir Crit Care Med 1999;159:992-1004.

40 Fedorov A, Beichel R, Kalpathy-Cramer J, et al. 3D Slicer as an image computing platform for the Quantitative Imaging Network. Magn Reson Imaging 2012;30:1323-41.

41 Kirby M, Svenningsen S, Owrangi A, et al. Hyperpolarized Helium-3 and Xenon-129 magnetic resonance imaging in healthy volunteers and subjects with chronic obstructive pulmonary disease. Radiology 2012;265:600-10.

42 Parraga G, Mathew L, Etemad-Rezai R, et al. Hyperpolarized 3 He magnetic resonance imaging of ventilation defects in healthy elderly volunteers: initial findings at 3.0 Tesla. Acad Radiol 2008;15:776-85

43 Kirby M, Mathew L, Wheatley A, et al. Chronic obstructive pulmonary disease: longitudinal hyperpolarized (3)He MR imaging. Radiology 2010;256: 280-89.

44 Mata J, Altes T, Knake J, et al. Hyperpolarized 3He MR imaging of the lung: effect of subject immobilization on the occurrence of ventilation defects. Acad Radiol 2008:15:260-64.

45 Peterson ET, Dattawadkar A, Samimi K, et al. Airway measures on MDCT in asthma at locations of ventilation defect identified by He-3 MRI. Am J Respir Crit Care Med 2010;181. doi:10.1164/ajrccm-conference.2010.181.1_MeetingAbstracts.A3958

46 Marshall H, Deppe MH, Parra-Robles J, et al. Direct visualisation of collateral ventilation in COPD with hyperpolarised gas MRI. Thorax 2012; 67:613-17

47 Macklem PT. The physiology of small airways. Am J Respir Crit Care Med 1998;157: S181-S83. 